aus dem Filtrate wird das Blei ebenfalls durch Zink reducirt und gewogen. Die Trennung von Antimon und Blei auf diesem Wege ist bekanntlich auch keine ganz scharfe.

\title{
Die Ursache der Differenzen bei Bestimmung des Silbergehaltes
} in Bleibarren findet $\mathrm{Sch}$ weitzer*) in der ungleichmässigen Vertheilung des Silbers in den Barren. Dasselbe sammelt sich besonders aussen an, findet sich in grösserer Menge oben als unten, in früher erstarrten Partieen mehr als in länger flüssig gebliebenen.**) In die Durchschnittszeichnung eines Bleiblickes eingeschriebene Silbergehalte erläutern die gemachten Angaben. Es enthielt in 1 Ton Blei Unzen Silber: die Oberflächenmitte 102,32; die Mitte 79,83; die untere Seite 96,33 ; lange Seite oben 104,54, unten 102,36; kurze Seiten oben 104,13, unten 100,32 .

Zur Bestimmung des Kohlenstoffes in Eisencarbureten. Pearse ${ }^{* * *}$ ) hat 36 Bestimmungen des Gesammt-Kohlenstoffes in Eisen- und Stahlsorten nach den verschiedensten Methoden ausgefuhrt. Die genauesten Resultate wurden erhalten bei Zerlegung des Carburets durch ein Doppelsalz von Kupferchlorid und Chlorammonium, Verbrennen des Kohlenstoffes mittelst Chromsäure und Schwefelsäure und Wägen der erhaltenen Kohlensäure. Nach den Angaben des Verfassers dauert das Lösen von 3-5 Grm. Eisen in der Kälte 10-15 Minuten, das Filtriren und $\mathrm{Zu}$ richten des Kohlenstoffes für die Verbrennung 25 Minuten und letztere $3 / 4-1$ Stunde.

Mc. Creath $\dagger$ ) bedient sich zur Bestimmung des gebundenen Kohlenstoffes für gewöhnlich der bekannten colorimetrischen Methode von Eg gertz. H) Diese setzt aber einen Normalstahl mit genau bekanntem Kohlenstoffgehalt voraus. Um letzteren exact $\mathrm{zu}$ bestimmen bedient sich Verfasser der Methode, welche auch nach den oben- besprochenen Versuchen von Pearse die genauesten Resultate liefert. Auch Mc. Creath hebt hervor, dass zur raschen Zersetzung von Eisencarbureten Kupferchlorid-Chlorammonium besonders geeignet sei. Der von ihm zur Oxy-

*) Amer. Chemist 1876 Nr. 72 p. 456.

**) Siehe Kerl's Probirkunst p. 12.

***) Eng. and Min. Journ. New-York 21, 151 und Berg- und Hüttenmänn. Ztg. 36, 43.

†) Eng. and Min. Journ. New-York 23, 168 und Berg- und Hüttenmänn. Ztg. 36, 268.

††) Diese Zeitschrift 2, 434 und 10, 245. 
dation des Kohlenstoffes mit Chromsäure und Schwefelsäure angewandte; im Original abgebildete Apparat weicht von dem. bekannten Ullgren' schen etwas ab.

Auch T. T. Morrel1*) bestimmt den gebundenen Kohlenstoff mittelst der Eggertz'schen colorimetrischen Probe, nur verwendet er statt der bestimmt gefärbten Normalflüssigkeiten gefärbtes Glas und zwar das gewöhnliche durch Silberoxyd bräunlichgelb gefärbte. Ist die richtige Färbung nicht direct $z \mathfrak{a}$ finden, so uberstreicht man die eine Seite so oft mit Carminlösung, bis der gewünschte Farbenton hervortritt. In ähnlicher Weise hat Verfasser schon früher gefärbte Glasstreifen bei einer von ihm vorgeschlagenen colorimetrischen Methode zur Bestimmung des Eisens benutzt. (Vgl. diese Zeitschrift 14, 390.)

Ryder**) bedient sich zur Bestimmung des Kohlenstoffes im Eisen des Magnetismus. Eine Eisenprobe mit einem Querschnitt von etwa $3 / 4$ Zoll im Quadrat und ron $3 \frac{1}{2}$ Zoll Länge wird eine Minute lang auf die Pole eines gewöhnlichen Elektromagneten gelegt und dadurch magnetisch gemacht. Dann nähert man das Stück einem in der Originalabhandlung näher beschriebenen Indicator und beobachtet die Ablenkung. Zeigt dann ein Normaleisenstïck von bekanntem Kohlenstoffgehalt nach 'gleicher Behandlung dieselbe Ablenkung, so ist der Koblen. stoffgehalt der untersuchten Probe gleich dem des Normaleisenstückes. Ueber die Genauigkeit dieses Verfahrens und über die Vergleichung desselben mit den anderen Methoden zur Bestimmung des Kohlenstoffes liegen keine Angaben vor.

Zur Bestimmung des Mangans im Spiegeleisen, Stabeisen und Stahl für technische Zwecke empfiehlt S. Kern ${ }^{* * *}$ ) folgendes Verfahren: $1 \mathrm{Grm}$. der zu untersuchenden Substanz wird in $30 \mathrm{CC}$. Salzsäure gelöst, wenn nöthig filtrirt, auf die Hälfte des Volums eingedampft, neuerdings filtrirt und das Filtrat mit aberschüssiger Kalilauge versetzt. Hierbei bleibt Thonerde, wenn vorhanden, gelöst, während ein Niederschlag von Eisenoxydul und Manganoxydul (beide oxydhaltig) entsteht. Dieser wird abfiltrirt, gewaschen, getrocknet,

*) Am. Chemist 5, 365; Berg- und Hüttenmänn. Ztg. 34, 230.

**) Eng. and Min. Journ. New-York 23, 27 und Berg- und Hüttenmänn. Ztg. 36, 58.

***) Chem. News 32, 100. 